\title{
Performance Evaluation of Construction and Demolition Debris as Substitute for Aggregate in Hot Mix Asphalt
}

\author{
Claude Villiers ${ }^{1 *}$, Jean Leon ${ }^{2}$ \\ ${ }^{1}$ Department of Environmental and Civil Engineering, Florida Gulf Coast University, 10501 FGCU Blvd S., Fort Myers, FL \\ 33965-6565, USA \\ ${ }^{2}$ Senior Inspector on Reconstruction of Tillary Project Phase III, CES Consultants, 45-10 Court Square, Long Island, NY \\ 11101, USA
}

Corresponding Author Email: cvillier@fgcu.edu

https://doi.org/10.18280/ijsdp.150603

Received: 24 December 2019

Accepted: 4 July 2020

\section{Keywords:}

recycle concrete aggregate, virgin aggregates, Superpave, volumetric properties, performance properties

\begin{abstract}
The purpose of this research project is to determine the validity and feasibility of using recycled concrete aggregate (RCA) in Hot Mix Asphalt (HMA) and to compare both the volumetric and performance properties of HMA mixtures constructed with (RCA) to conventional HMA mixtures. To achieve this objective, two HMA mixes were selected with one containing only virgin aggregates and the other made with a combination of $80 \%$ of virgin aggregate and 20\% RCA. Based on the analysis conducted, RCA has rougher surface textures and lesser amount of flat and elongated and more angular shape particles. These characteristics of the RCA created a stronger aggregate skeleton in the aggregate distributions, which in turn increased the VMA and the resistance to permanent deformation in the mixture. RCA mixture had demonstrated greater rutting resistance as compared to the virgin mix. RCA was very sensitive when it was subjected to water damage. Tensile strength ratio (TSR) values were reduced by over $40 \%$ on the mixture containing RCA. Further testing and investigation are needed to fully understand the conditions of this reduction. This research showed that the Department of Transportation would achieve significant saving if RCA is used in HMA mixtures.
\end{abstract}

\section{INTRODUCTION}

Recycled concrete aggregate (RCA) also known as reclaimed concrete aggregate is produced by crushing concrete from demolished structures such buildings, bridges, pavements, dams and other structural concrete after removal of reinforcing steel. Annual production of RCA in the United States from all sources (both pavements and demolition debris) was recently reported as about 140 million tons [1]. Countries such as China, India, Indonesia, Malaysia, Thailand, Gulf States, Turkey, Russia, Brazil, and Mexico have recorded some of the strongest increases in the demand for waste recycling [2]. One option is to dispose of these materials in landfills. However, landfills and waste materials have become very costly and heavily regulated. Another problem is that today more hot mix asphalt pavements are being built or reconstructed in the nation. These conditions create a higher demand for aggregate that consists of about $95 \%$ of hot mix asphalt (HMA) mixtures. In addition to depleting our natural resources, operating the heavy diesel-powered 50-ton-capacity haul trucks, diesel-powered hydraulic shovels, heavy duty drills, crushers, compressed air powered hammers, crawlermounted hydraulic machines, and special water spray trucks often found at a quarry operation requires using a lot of energy. Developing effective alternative solutions to the disposal of concrete would be beneficial both economically and ecologically.

Currently the main use of recycle concrete aggregates (RCA) is as base materials [3-5]. And although the use of RCA is encouraging, only a handful of states allow its use in surface courses for asphalt and concrete mixes [3-7]. About $9.7 \%$ of RCA is used on asphalt concrete [6]. It may be difficult to convince mix designers and HMA producers to consider the use of RCA in the surface course for roadway pavements because little or no information exists in the literature on the application of RCA on pavements. There are other valid reasons to be careful in using RCA. Many contractors in City and State Departments of Transportation (DOT) have very good intentions of using RCA in HMA; however, it is not as simple as it may appear. During a conversation with a contractor in the local area who was experiencing RCA in HMA applications, the contractor expressed concern regarding the temperature at which RCA should be heated during plant production. Due to the fact that adhesion of mortar to the aggregates incorporated in the concrete RCA has higher asphalt absorption than virgin aggregates the cost saving does not sound appealing. Some authors have concluded that RCA can be used to produce quality HMA mixes [7-9]. This paper consists of a complete characteristic of the physical properties of RCA and guideline to effectively design HMA mixtures with RCA while maintaining the performance of the mixtures. Volumetric properties such as air voids and Voids filled with asphalt along with creep compliance and tensile strength was used as performance measure. The results show that RCA appears to be suitable to use in asphalt concrete mixture. 


\section{OBJECTIVES}

The primary objectives of this work are to:

- Characterize the physical properties of recycled crushed concrete aggregates.

- Evaluate the volumetric properties along with water damage, rutting and cracking susceptibility of HMA mixtures constructed with RCA.

\section{MATERIALS}

The virgin materials (coarse and fine aggregates) used in this research was limestone mined by a local quarry in Southwest Florida. The natural coarse and fine aggregates have been approved by the Florida Department of Transportation (FDOT) and are classified as S1-A Stone and No. 131 - Screening, respectively. The recycled crushed concrete (RCA) used on this research was originated exclusively from concrete building demolitions. A Superpave mixture that was already placed on state highways in the state of Florida was selected. This mixture was part of a Superpave Monitoring Project in the State of Florida. Since the actual materials during production of this mix were not available, the gradation of this field mixture was reproduced in the laboratory using available virgin and RCA aggregate. All the necessary measures were taken to ensure that the parameters including gradation, asphalt content, specific gravity of the aggregate, percentage air void (AV), voids in mineral aggregate (VMA), and voids filled with asphalt (VFA) of reproduced mixture was equal or close to this field mix. The asphalt binder was graded PG-64-22.

\section{RESULTS}

\subsection{Aggregate physical properties}

The potential of aggregate breakdown under loading and surface texture were assessed using the procedures from the American Society for Testing and Materials, respectively [10, 11]. The Superpave Aggregate Consensus properties, such as coarse aggregate angularity test, flat \& elongate test were conducted on both the virgin and recycled crushed concrete. Table 1 presents the percentage of flat and elongate particles (F\&E). The RCA has a lower percentage of F\&E particles which implies that the aggregate shapes are more cubical as compared to the virgin aggregate. A lower F\&E particle will also increase the VMA in the mixture and, as a result, may enhance the rutting resistance in the mixture. Table 1 also presents the fracture faces of the coarse particles for both the RCA and Virgin aggregate. Both aggregate types have a high percentage (over $80 \%$ ) of crushed aggregate particles with 3 or more faces. This information may in turn maximize the shear strength of the mixtures.

Additional physical properties tests, such as specific gravity, absorption, and grain size distribution (gradation) were conducted. The bulk specific gravity, a measure of the volume occupied by the aggregate in the mixture, and the absorption were evaluated using the American Association of State Highway and Transportation Officials standard specifications for coarse and fine aggregates, respectively $[12,13]$. It must be noted that RCA has a lower (13\%) specific gravity and much higher $(52 \%)$ absorption as compared to the virgin aggregate (see Table 2). This observation was consistent with the literature $[3,4,7-9]$. Since the new mixture which contains the RCA is more absorptive (mortar adhering to aggregates) than the virgin mix, it is also expected that this mix will need a higher asphalt content to meet the Superpave volumetric mix design requirements. The other properties of the aggregates are presented in Table 2. The properties of the RCA were comparable to the virgin aggregate (limestone) used in this project. Both the limestone and RCA were tough and had a high resistance to crushing and degradation. The LA Abrasion values were 36.0 and 35.9 for the S1-A Stone and RCA, respectively. The RCA and virgin aggregate had similar size particles.

Table 1. Aggregate consensus properties

\begin{tabular}{|c|c|c|c|c|c|c|}
\hline & \multicolumn{2}{|c|}{$\begin{array}{l}\% \text { Flat and } \\
\text { Elongate }\end{array}$} & \multicolumn{4}{|c|}{$\begin{array}{c}\% \text { Fractured Particles in Coarse } \\
\text { Aggregate }\end{array}$} \\
\hline & $5: 1$ & $3: 1$ & 0 & 1 & 2 & $3+$ \\
\hline Virgin $^{a}$ & 5 & 57 & 1 & 3 & 14 & 82 \\
\hline $\mathrm{RCA}^{\mathrm{b}}$ & 1 & 17 & 6 & 4 & 5 & 85 \\
\hline
\end{tabular}

Note: ${ }^{\text {VVirgin }}=100 \%$ Virgin Aggregate; ${ }^{b} \mathrm{RCA}=$ Recycled Concrete Aggregate

Table 2. Other physical properties of aggregate

\begin{tabular}{|c|c|c|c|}
\hline & \multicolumn{3}{|c|}{ Type of Aggregate } \\
\cline { 2 - 4 } & $\begin{array}{c}\text { S1-A } \\
\text { (Virgin) }\end{array}$ & $\begin{array}{c}\text { RC } \\
\text { A }\end{array}$ & $\begin{array}{c}131-\text { Screening } \\
\text { (Virgin) }\end{array}$ \\
\hline Maximum Size, mm & 19 & 19 & N/A \\
\hline Fineness Modulus & 6.98 & 4.95 & 2.60 \\
\hline Bulk Specific Gravity & 2.400 & $\begin{array}{c}2.09 \\
5\end{array}$ & 2.422 \\
\hline Absorption, \% & 5.5 & 8.4 & 4.3 \\
\hline Los Angeles Abrasion & 36.0 & 35.9 & N/A \\
\hline $\begin{array}{c}\text { Maximum Dry Density, } \\
\text { (Kg/m })^{3} \text { ) }\end{array}$ & 1557.0 & $\begin{array}{c}190 \\
1.4\end{array}$ & N/A \\
\hline $\begin{array}{c}\text { Optimum Moisture } \\
\text { Content, } \%\end{array}$ & N/A & 11.3 & N/A \\
\hline $\begin{array}{c}\text { Passing No. 200 } \\
\text { Sieve, } \%\end{array}$ & 5.7 & 4.3 & N/A \\
\hline $\begin{array}{c}\text { Limerock Bearing Ratio } \\
\text { (LBR), \% }\end{array}$ & N/A & 112 & N/A \\
\hline Total Carbonates, \% & N/A & 54 & N/A \\
\hline
\end{tabular}

Note: N/A = Not applicable

Based on the information presented in the literature review, $40 \%$ RCA appears to be a feasible quantity, beyond which the mix may become unstable and/or uneconomical, since crushed concrete aggregate is more absorptive than the virgin aggregate, consequently requiring more asphalt binder in the mix $[7-9,14]$. Some authors have concluded that permanent deformation resistance, compression loads, and water sensitivity are favored by the incorporation of recycled concrete aggregates in hot mix asphalt mixtures only until $40 \%$ of RCA [7-9]. Therefore, on this research a combination of $80 \%$ of natural aggregate and $20 \%$ of RCA is selected for the mixture used. Moreover, Asphalt paving contractors have typically used up to $20 \%$ to $30 \%$ recycled material in the mixes. As has been mentioned before, the virgin mix selected in this research was from a real mixture that had already been placed in the roadway of the State of Florida. Once the virgin mixture was successfully redesigned using the Superpave Mix design criteria [15-17]. The aggregate composition was modified by incorporating $20 \%$ RCA into the mixture. Trial and error process were used to ensure that the gradation and the total weight of the aggregate of the modified mixture 
remained constant. Figure 1 shows the gradation chart along with the Superpave Restricted Zone and Control Points.

\subsection{Volumetric properties}

Each of the mixtures was mixed at temperature of $150^{\circ} \mathrm{C}$ $\left(300^{\circ} \mathrm{F}\right)$ as was specified in the original mix design. The asphalt binder that was used in all the mixtures was graded PG64-22. All the mixtures were subjected to short term oven aged (STOA) and compacted using the Superpave gyratory compactor at N-design of 75 gyrations. The number of gyrations for this traffic level corresponds to a traffic level C ("low volume road") according to the Florida DOT specification [18]. This level of effort was also selected based on the requirements of the original mix design criteria. This level of gyration represents a compactive effort for roadways with traffic volumes between 3 to 30 millions equivalent single axle loads (ESALs).

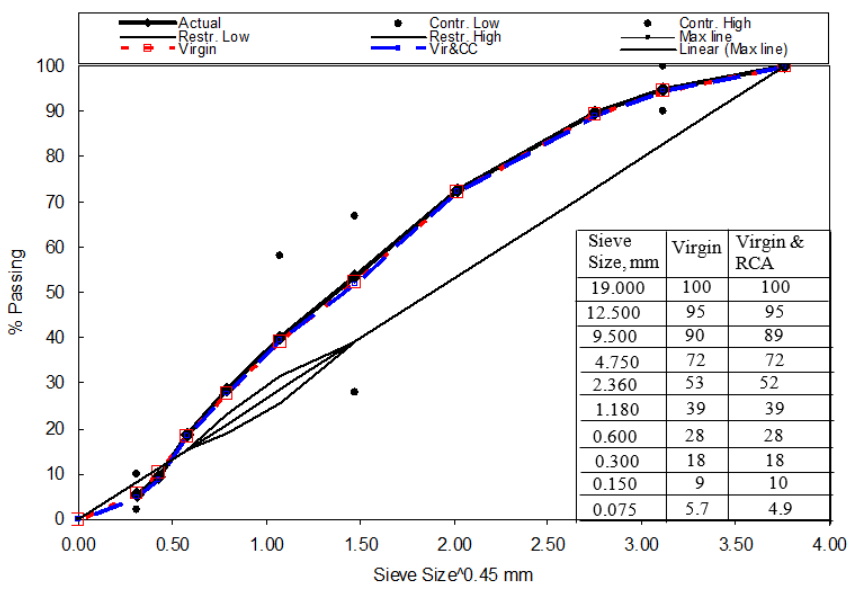

Figure 1. Aggregate gradation

Table 3. Volumetric properties for virgin \& RCA mixtures

\begin{tabular}{|c|c|c|}
\hline & Virgin $^{\mathrm{a}}$ & RCA Mix $^{\mathrm{b}}$ \\
\hline $\mathrm{AC}$ & 5.4 & 6.0 \\
\hline $\mathrm{G}_{\mathrm{mm}}$ & 5.636 & 2.548 \\
\hline $\mathrm{G}_{\mathrm{mb}}$ & 2.519 & 2.434 \\
\hline Va at $\mathrm{N}_{\text {des }}=75$ & 4.4 & 4.5 \\
\hline VMA & 16.9 & 18.9 \\
\hline VFA & 73.56 & 76.28 \\
\hline $\mathrm{D} / \mathrm{A}$ & 1.2 & 1.1 \\
\hline$\% \mathrm{G}_{\mathrm{mm}}$ at $\mathrm{N}_{\text {ini }}$ & 89.05 & 89.28 \\
\hline
\end{tabular}

Note: ${ }^{a}$ Virgin $=100 \%$ Virgin Aggregate; ${ }^{b}$ RCA Mix $=20 \%$ Recycled Concrete Aggregate and $80 \%$ Virgin Aggregate

Table 3 presents the volumetric properties such as air void (Va), voids in the mineral aggregate (VMA), and voids filled with asphalt (VFA). Other additional parameters including the ratio of the effective dust to asphalt content (D/A) and the compaction parameters such as the $\% \mathrm{Gmm}$ at $\mathrm{N}$-initial are also included. As can be seen in the Table, both mixtures met the $4.0 \pm 0.5 \%$ Air Void requirements. Other volumetric properties such as the dust to asphalt content, VMA, and VFA were within the limits of the Superpave mix design criteria or close to the original mix. It was also noted that the RCA mix has much higher VMA and VFA as compared to the Virgin mixture. This may be the results of higher angularity and rougher texture of the RCA as compared to virgin aggregate. The integration of the RCA in the mix improved the air void space to hold plastic properties and created a stronger aggregate skeleton without opening up the mix (gap graded) which in turn may improve the mix resistance to permanent deformation.

\subsection{Rutting resistance}

Creep test in indirect tensile (IDT) mode has been successfully used to characterize mixtures at low temperatures. Once the mixtures were successfully designed, a total of 16 samples ( 8 for each) were prepared to assess the performance evaluation of the mixtures. A modified version of the LongTerm Pavement Performance test method was used for determining creep compliance of asphalt materials using the indirect tensile test device $[19,20]$. This "simple device" was first developed and successfully used for the Wisconsin Department of Transportation (WisDOT) as an alternative for evaluating asphalt concrete mixtures at the laboratory, plant, and in the field [21]). The recommendations of the test methods and the device were based primarily on its capability of measuring accurate and repeatable properties that affect pavement performance. In addition, factors such as specimen preparation, testing time, and ease of operation were also considered.

The specimens were compacted in a 6-inch $(150 \mathrm{~mm})$ diameter mold to $7 \% \pm 0.5 \%$ air void. The samples were trimmed to meet the sample size requirements [21]. Once specimens were compacted, they were cored and cut with a diamond blade saw to have 6 -inch $(150 \mathrm{~mm})$ lengths with flat, smooth, and parallel ends. The specimen was placed in the IDT temperature chamber for at least 8 hours. This was required to assure temperature stability in the specimen. The creep test was performed on the specimens at a temperature of $25^{\circ} \mathrm{C}\left(77 \pm 1^{\circ} \mathrm{F}\right)$. In the creep test, a static load was applied to the HMA specimen and the resulting time-dependent deformation was measured. A constant static load was applied to the specimen for 1000 seconds and the horizontal deformation was recorded.

By definition, Creep Compliance is a function of timedependent strain $\left(\varepsilon_{t}\right)$ divided by a constraint stress $(\sigma)$. The compliance was calculated t by dividing the strain by the applied stress as shown in Eq. (1). The Creep Compliance could be used to express the ability for mixtures to relax stress, especially thermal stresses. In this study, it was used to evaluate the rate of damage accumulation in the asphalt mixtures. The summary test results are presented in Figure 2. As can be seen from the test results, one can predict that the RCA mixture may have a better resistance to rutting deformation. The RCA mixture creep compliance values were much lower (about 100\% lower on average) as compared to virgin mix. The improvement on the creep compliance on the RCA mixture may be associated with the higher angular shape of the process RCA and rougher texture of the mixture containing RCA as compared to the virgin mix.

$$
D(t)=\frac{\varepsilon_{t}}{\sigma}
$$

where:

$\mathrm{D}(\mathrm{t})=$ creep compliance

$\mathrm{t}=$ time, second

$\varepsilon_{\mathrm{t}}=$ strain at time, $\mathrm{t},(\mathrm{inch} / \mathrm{inch})$, and

$\sigma=$ Applied stress, psi 


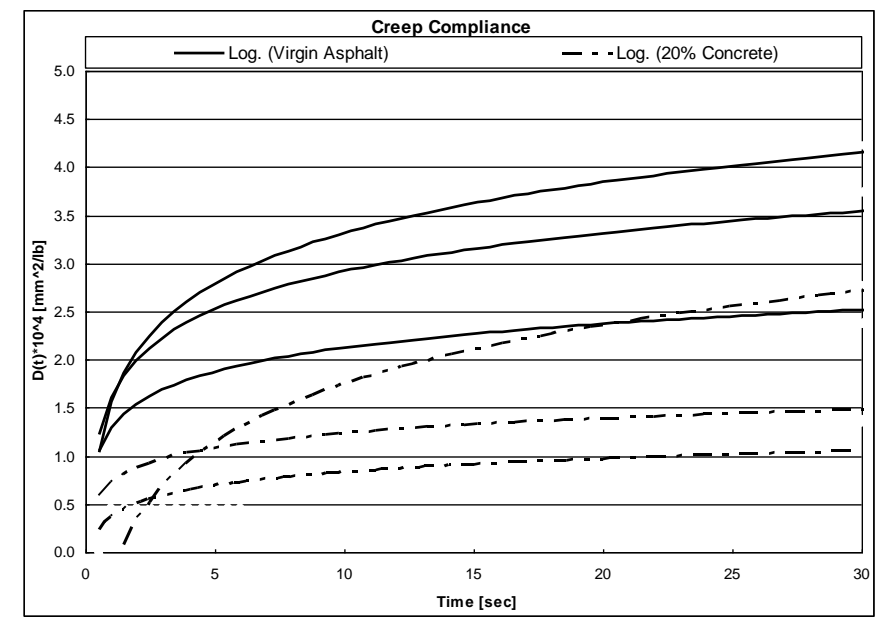

Figure 2. Creep compliance

\subsection{Moisture-induced damage evaluation}

Water Damage Test was conducted to evaluate the effects of saturation and accelerated water conditioning, with a freezethaw cycle of compacted asphalt mixtures. The specimens were cut by the saw machine at $100 \mathrm{~mm}$ (4 inches) in diameter by $63.5 \pm 2.5 \mathrm{~mm}(2.5 \pm 0.1 \mathrm{in}$.). The specimens were divided into two categories, the conditioning samples (C) and unconditioning ones (U) for both mixes. One subset was dry tested, and the other one was partially vacuum-saturated, subjected to freezing, and soaked in warm water before testing. The degree of saturation required for proceeding with the test is within 70 and 80 percent to make sure all pores of the specimen were filled with water. All the necessary measurements were taken to ensure that the degree of saturation was in the range for each specimen. Both conditioning and un-conditioning samples were loaded to failure. The compressive strength was determined. The water damage rate accumulation also known as tensile strength ratios (TSR) was then determined based on Eq. (2).

$$
\operatorname{TSR}(\%)=\frac{S_{1}}{S_{2}} * 100
$$

where:

$\mathrm{TSR}=$ tensile strength ratio,

$\mathrm{S}_{1}=$ compressive strength of dry specimen (group U), and $\mathrm{S}_{2}=$ compressive strength immersed specimen (group C).

The tensile strength ratios (TSR) were used to evaluate the damage due to water or moisture in the HMA mixtures. The average Strength and TSR values, along with the $95 \%$ confidence interval error bars for the virgin mix and the one containing 20\% of RCA, are presented in Figures 3 and 4, respectively. As shown in Figure 3, a higher strength result was reported in the mixture containing the recycled crushed concrete as compared to the virgin mix. This is an indication that the integration of RCA in a mixture may enhance the strength resistance of the mixture and, as a result, may improve the mixture resistance to rutting. As mentioned earlier, the high angular and rough texture of the RCA may be the contributing factor for this trend. Similar observation was reported by other authors $[22,23]$.

A higher $(40 \%)$ reduction in strength was observed in the RCA mixture when it was subjected to moisture conditioning as compared the virgin mix. Nevertheless, only a small reduction in TSR was observed in the mixture containing RCA. It was noted the TSR values for both mixtures were below or close to the $60 \%-80 \%$ TSR normally required for HMA surface course. The causes for this failure were beyond the scope of this study. The objective was simply to compare the performances of a virgin mix to those of a mixture containing RCA.

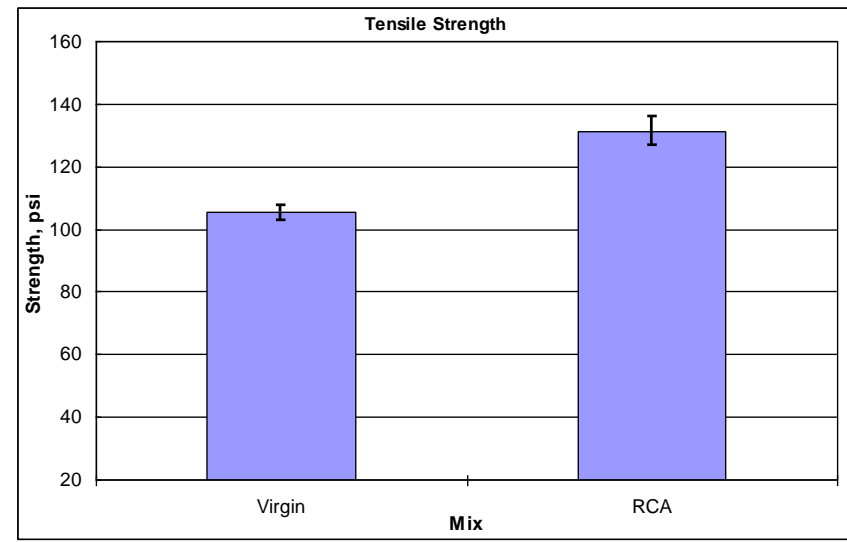

Figure 3. Tensile strength along with $95 \%$ confidence interval error bars

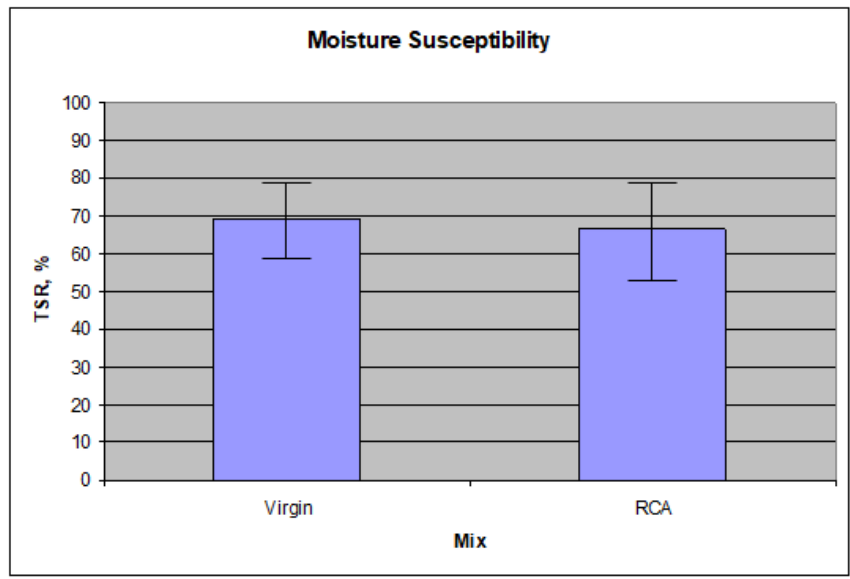

Figure 4. Moisture susceptibility ratio along with $95 \%$ confidence interval error bars

\section{DISCUSSION}

This experiment was constructed to determine the validity and feasibility of using RCA in HMA for roadway applications. The mixture used in this research was an actual mix that was successfully placed and accepted in the field. This mixture was reproduced with the same asphalt content, gradation, air void, and other volumetric properties. Another mixture was generated by substituting $20 \%$ of RCA and $80 \%$ Virgin aggregates. All the necessary measurements were taken to ensure that the parameters in this modified mix were in compliance with the Superpave mix design criteria

Successful HMA mixtures were created. They met the Superpave consensus aggregate and volumetric properties using RCA from building demolition. RCA has rougher surface textures and lesser amount of flat and elongated and more angular shape particles. These characteristics of the RCA appeared to create a stronger aggregate skeleton in the aggregate distributions, which in turn increased the VMA and 
the resistance to permanent deformation in the mixture. This observation was consistent with the literature. It was reported that RCA structure, texture, rough surfaces, and sharp edges increased the specific surface area and friction between aggregate particles and helped to improve resistance to permanent deformation [7, 24].

Both mixtures Virgin mixture and the RCA mixture met the $4.0 \pm 0.5 \%$ Air Void Superpave requirements. Other volumetric properties such as the dust to asphalt content, VMA, and VFA were within the limits of the Superpave mix design criteria or close to the original mix. The VFA in the RCA mix was slightly in the high side of the limit. However, since the VFA in the original mix was 76 , it was not necessary to make any modification to lower the VFA. Under normal practice, this RCA mix would be approved, successfully placed and accepted in roadway. It was also noted that the RCA mix has much higher VMA and VFA as compared to the Virgin mixture. This observation was due to the fact that the RCA aggregate is more porous and higher absorption. In addition due to the fact that the angularity and rougher texture, the integration of the RCA in the mix improved the air void space to hold plastic properties and created a stronger aggregate skeleton without opening up the mix (gap graded) which in turn may improve the mix resistance to permanent deformation.

Additional tests which include creep compliance and moisture damage were also performed in the mixtures. The mixture that contains RCA was more resistant to permanent deformation. On average, the creep compliance values were $100 \%$ lower in the RCA mixture as compared to the Virgin mix. Also, the strength values increased by about $25 \%$ in the RCA mix. This improvement in the mix appeared to be the contributing factor of the aggregate structure of the RCA. Again being more angular, there may be a higher stone to stone contact of the aggregate in the mixture that may increase the resistance to rutting deformation in the mix.

There was a substantial decrease in the strength in the RCA mix when subjected to water damage. RCA aggregate which contains additional cement paste from original concrete mix minimized the bonding strength of the RCA mix. Similar observation was made in the literature [7]. Other researchers have reported that RCA less durable compared to natural aggregate $[25,26]$. Furthermore, the TSR values in RCA mix, although lower, were fairly close to the virgin mix. As reported in the literature, the predominant chemical compound of typical RCA is calcium [7]. It appears that higher absorption in the mix and higher porosity of the RCA may play a factor in keeping the TRS at comparable level. The already mentioned quality of the aggregate shape and texture of the RCA certainly add to this behavior. This research showed that the Department of Transportation would achieve significant saving if RCA is used in HMA mixtures. The use of RCA will eliminate the development of waste stockpiles of concrete, creating a friendly environment.

\section{CONCLUSIONS AND RECOMMENDATIONS}

This study focused validity and feasibility of using RCA in HMA for roadway applications. This is very limited data. However, based on test results, the following conclusions and recommendations were drawn:

- A successful Superpave mix was generated using the combination of $80 \%$ virgin and $20 \%$ recycled concrete aggregate. The integration of the RCA into the mix increased the mixture stone to stone contact of the aggregate and VMA without weakening the aggregate skeleton.

- On average, the creep compliance values decreased by about $100 \%$ in the mix containing RCA as compared to the Virgin mix. Also, the strength values increase by about $25 \%$ in the RCA mix. Based on the aggregate consensus tests that were conducted, it was noted that the RCA was more angular and rougher in texture. These characteristics may improve the mixture resistance to rutting deformation.

- RCA was very sensitive when it was subjected to water damage. TSR values by over $40 \%$ on the mixture containing RCA. The conditions of this drop are not fully understood and require further investigation.

- These findings were also supported by the literature. Further testing and investigation are recommended. This research gives credence that RCA can be used in HMA mixes. It also shows that the Department of Transportation would achieve significant saving if RCA is used in HMA mixtures.

\section{ACKNOWLEDGMENT}

The authors would like to acknowledge the University of Florida Research team and the Florida Department of Transportation for providing the information about mix design. The authors would also like to thank Dr. Yusuf Mehta and Dr. Neville Parker for their guidance.

\section{REFERENCES}

[1] Federal Highway Administration - American Concrete Pavement Association (2017). Recycled concrete aggregate usage in the USA industry and DOT survey. National Concrete Pavement Technology Center. Iowa State University. Ames, IA. http://www.acpa.org/wpcontent/uploads/2017/10/Draft_RCA-Report-2016.pdf, accessed on Mar. 21, 2020.

[2] Tama, V., Soomro, M., Evangelist, A. (2018). A review of recycled aggregate in concrete applications (2000 2017). Construction and Building Materials, 172: 272292. https://doi.org/10.1016/j.conbuildmat.2018.03.240

[3] Courard, L., Rondeux, M., Zhao, Z., Michel, F. (2020). Use of recycled fine aggregates from C\&DW for unbound road sub-base. Materials, 13(13): 2994. https://doi.org/10.3390/ma13132994

[4] Pavlů, T., Kočí, V., Hájek, P. (2019). Environmental assessment of two use cycles of recycled aggregate concrete. $\quad$ Sustainability, $11(21)$ : 6185. https://doi.org/10.3390/su11216185

[5] Zhao, Z., Courard, L., Groslambert, S., Jehin, T., Léonard, A., Xiao, J. (2020). Use of recycled concrete aggregates from precast block for the production of new building blocks: An industrial scale study. Resources, Conservation and Recycling, 157: 104786. https://doi.org/10.1016/j.resconrec.2020.104786

[6] Snyder, Ma., Cavalline, T., Fick, G., Taylor, P., Gross, J. (2018). Recycling concrete pavement materials: A practitioner's reference guide. National Concrete Pavement Technology Center, Iowa State University. 
Part of DTFH61-12-H-00010. Ames, IA. https://intrans.iastate.edu/app/uploads/2018/09/RCA_pr actioner_guide_w_cvr.pdf, accessed on Mar. 21, 2020.

[7] Álvarez, D., Aenlle, A., Tenza-Abril, A., Ivorra, S. (2020). Influence of partial coarse fraction substitution of natural aggregate by recycled concrete aggregate in hot asphalt mixtures. Sustainability, 12(1): 250. https://doi.org/10.3390/su12010250

[8] Al-Bayati, H., Tighe, S., Achebe, J. (2018). Influence of recycled concrete aggregate on volumetric properties of hot mix asphalt. Journal of Resources, Conservation and Recycling, 130:

200-214. https://doi.org/10.1016/j.resconrec.2017.11.027

[9] El-Tahan, D., Gabr, A., El-Badawy, S., Shetawy, M. (2018). Evaluation of recycled concrete aggregate in asphalt mixes. Innovative Infrastructure Solutions, 3(1). https://doi.org/10.1007/s41062-018-0126-7

[10] ASTM D5821, Standard Test Method for Determining the Percentage of Fractured Particles in Coarse Aggregate. ASTM International. West Conshohocken, PA, 2017. www.astm.org, accessed on Mar. 21, 2020.

[11] ASTM D4791, Standard Test Method for Flat Particles, Elongated Particles, or Flat and Elongated Particles in Coarse Aggregate. ASTM International. West Conshohocken, PA, 2019. www.astm.org, accessed on Mar. 21, 2020.

[12] AASHTO T 85, Standard Method of Test for Specific Gravity and Absorption of Coarse Aggregate. Washington, D.C., 2014.

[13] AASHTO T 84, Standard Method of Test for Specific Gravity and Absorption of Fine Aggregate. Washington, D. C., 2013.

[14] Martinho, F., Picado-Santo, L., Capitão, S. (2018). Feasibility assessment of the use of recycled aggregates for asphalt mixtures. Journal of Sustainability, 10(6): 1737. https://doi.org/10.3390/su10061737

[15] Federal Highway Administration. (2010). Superpave Mix Design and Gyratory Compaction Levels. TechBrief No. FHWA-HIF-11-031., Washington, D.C.

[16] Hossain, M., Fager, G. (2017). Superpave Volumetric Mixture Design and Analysis Handbook. Superpave Laboratory Study Manual (Volume III) Manhattan, KS. https://cpb-us-e1.wpmucdn.com/conferences.kstate.edu/dist/d/39/files/2016/02/310_Vol-III-LabStudy-Manual-Oct-2016-2msdlhg.pdf, accessed on Mar. 21, 2020.

[17] Tran, N., Huber, G., Leiva, F., Pine, B., Yin, F. (2019). Mix design strategies for improving asphalt mixture performance. National Center for Asphalt Technology. NCAT Report 19-08. Auburn, AL. https://www.eng.auburn.edu/research/centers/ncat/files/t echnical-reports/rep19-08.pdf, accessed on Mar. 21, 2020.
[18] Florida Department of Transportation (2019). Standard Specifications for road and bridge construction. Article 334, FDOT Specification Office, Tallahassee, FL. Website:

https://fdotwww.blob.core.windows.net/sitefinity/docs/d efault-

source/programmanagement/implemented/specbooks/ju ly-2019/719ebook.pdf?sfvrsn=bf366a48_2, accessed on Mar. 21, 2020.

[19] Federal Highway Administration. (2001). Test Method for Determining the Creep Compliance, Resilient Modulus and Strength of Asphalt Materials Using the Indirect Tensile Test Device. Federal Highway Administration - Long Term pavement Performance FHWA-LTPP, Protocol P07. Version 1.1.

[20] Teshale, E., Stolarski, H., Marasteanu, M. (2013). Determination of creep compliance of asphalt concrete from notched semi-circular bend (SCB) test. Exp Mech, 53: 919-928. https://doi.org/10.1007/s11340-012-9688-Z

[21] Mehta, Y., Sukumaran, B., Liddle, J., Stevenson, J., Investigation of New Devices for Use in Determining Mechanistic Properties and Performance. Wisconsin Highway Research Program - SPR\# 0092-03-15 Report No. WHRP 06-10, November, 2005. http://digital.library.wisc.edu/1793/53458, accessed on Mar. 21, 2020.

[22] Lim, S., Kestner, D., Zollinger, D., Fowler, D., Characterization of crushed concrete materials for paving and non-paving applications. A report submitted to the Texas Department of Transportation, Austin, TX. Report No. TX-04/7-4954-1, January 2003.

[23] ArabaniA, M., Azarhoosh, R. (2012). The effect of recycled concrete aggregate and steel slag on the dynamic properties of asphalt mixtures. Construction and Building Materials, 35: 1-7. https://doi.org/10.1016/j.conbuildmat.2012.02.036

[24] Radevic, A., Durekovic, A., Zakic, D., Mladenovic, D. (2017). Effects of recycled concrete aggregate on stiffness and rutting resistances of asphalt concrete. Construction and Building Materials, 136: 386-393. http://dx.doi.org/10.1016/j.conbuildmat.2017.01.043

[25] Verian, K. (2015). Influence of air-cooed blast furnace Slag (ACBFS) coarse aggregate on properties of pavement concrete exposed to freezing-thawing and wetting-drying conditions. Ph.D. Dissertation. Purdue University (206 p).

[26] Veriana, K., Ashraf, W., Cao, Y (2018). Properties of recycled concrete aggregate and their influence in new concrete production. Resources, Conservation \& Recycling. Resources, Conservation and Recycling, 133: 30-49. https://doi.org/10.1016/j.resconrec.2018.02.005 